\title{
How Smokers Became Outlaws: An Application Of The Stakeholder Salience Model To A Social Problem
}

Susan K. Key, University of Alabama at Birmingham, USA

Rosalia N. Scripa, University of Alabama at Birmingham, USA

Robert Juneau, University of Alabama at Birmingham, USA

\begin{abstract}
Smoking bans have gone from being essentially non-existent to being the norm over the course of the last 50 years. When some of these authors started teaching, it was the norm to smoke in the classroom, in hospitals, on airplanes, in prison and in the office. Times have changed-smoking is no longer allowed in these locations in the United States. In this paper, an overview of the history of smoking advocacy, the impacts of smoke-free legislation on different stakeholders, and changes in public perceptions of smoking are provided. Mitchell and Agle's 1997 Stakeholder Salience Model are used to illustrate the changes over time in stakeholder status for both smokers and nonsmokers. The Mitchell Model could have been useful to predict the change in status that the two stakeholder groups experienced and the authors suggest that management should note the emergence of urgent stakeholders in the future, as they may gain salience in other matters that can impact company wealth. Firms have to be aware of both their customers' needs (smokers) as well as other social movements that may affect the use of their product, such as nonsmoking legislation. This is the first paper to apply stakeholder salience, including the concepts of urgency, power, and legitimacy, to the changing fortunes of smokers. It looks at how smoking and smokers have gone from the norm in U.S. society to outlaw status.
\end{abstract}

Keywords: Stakeholders; Stakeholder Salience; Smokers; Nonsmokers

\section{BACKGROUND}

$\mathrm{n}$ recent years, cities and states have passed smoke-free business legislation, with the least opposition arising when smoking is banned in businesses that serve children, such as day care centers, and the most opposition arising when smoking is banned in businesses that are otherwise adults only, such as bars. Smoke-free legislation is a relatively recent phenomenon that got its impetus from the 1962 Royal College of Physicians of London's report "Smoking and Health" in the United Kingdom and the 1964 Surgeon General's "Smoking and Health" report in the United States (U.S. Public Health Service) and gained strength with the health and exercise movements in the United States. The purposes of our paper are to 1) explore the nature of the stakeholder relationship between anti-smoking groups and business, 2) demonstrate how the emergence of antismoking groups fits within the stakeholder framework, and 3) show how this example of regulatory change on business can be used to predict outcomes of other regulatory changes in the business environment.

\section{NONSMOKING ADVOCACY AND SMOKING BANS}

Major non-smoking advocacy efforts have been in place in most parts of the world for almost 50 years with many forming in the wake of the scientific reports mentioned earlier. In the last several years, the incidence of smoke-free legislation has increased nationally and internationally, with most of the focus on developed countries. Two impacts are observed from smoke-free legislation-economic and health. Smoking bans have been found to have a neutral to negative economic impact, with most studies showing the short-term, direct economic impact on 
bars and restaurants as negative - for example, in Germany, as demonstrated by Kvasnicka and Tauchmann (2012) or in Ireland, as shown by Cornelson and Normand (2012). However, an analysis of VAT receipts of South African restaurants by Belcher (2006), following their 1999 partial ban, showed negligible impact on restaurant and bar revenues (2006); and one study, with otherwise neutral results by Adams and Cotti (2007), showed that communities in the United States with a low prevalence of smokers saw an increase in restaurant and bar employment in the wake of smoking bans (2007).

The health impacts of reducing smoking are fairly clear, with one recent study from Adams, Cotti, and Furman (2013) showing a notable decrease in the number of myocardial infractions after smoking bans are put in place, although it seems that statewide bans have a lower marginal effect than initial municipal bans. Another study by Taylor et al. (2012), comparing El Paso (with a smoking ban) to San Antonio and Austin (without bans) over a period of ten years, found a $6 \%$ improvement in smoking cessation numbers.

One other notable trend with smoking bans is that they become more popular the more they are implemented. Mons, Nagelhaut, et al. (2012) performed a survey of European smokers that shows they tend to prefer comprehensive smoke-free bans to partial bans and that this support increases after legislation is implemented. A related study by Allwright (2008) shows that partial bans, or areas where bars may opt-in as smoking allowed, quickly see the smoking-allowed option become the norm again. This may be without regard to the wishes of the citizenry and the proprietors. In France, Kennedy et al. (2012) have shown that preference for some form of outdoor smoking ban has reached $75 \%$ among smokers as smoking moved outdoors following an indoor ban. In the United States, similar trends have been observed (Allwright, 2008).

\section{THE STAKEHOLDER SALIENCE MODEL}

No model provides a better way to analyze the environment involving smokers and non-smokers than the Stakeholder Salience Model. While there are numerous approaches to the stakeholder model in the literature, the most valuable approach for displaying the shift in attitudes towards smoking and smoking bans is the Stakeholder Salience Model, as espoused in Mitchell, Agle, and Wood's Towards a Theory of Stakeholder Identification and Salience: Defining the Principle of Who and What Really Counts (1997) and then refined in later papers. Their approach to stakeholders defines Stakeholder Salience as "the degree to which managers give priority to competing stakeholder claims" (1997: 869). Mitchell et al. take a wide view of what constitutes a stakeholder, using Freeman's (1984) definition of "any group who can affect or is affected by the achievement of the organization's objectives", although they do explore some of the narrower views provided by authors subsequent to Freeman. Through their research, they determined that no single variable can reliably predict or guide what a manager will consider a stakeholder, creating the need for a full typology of stakeholder salience (1997).

Ultimately, the typology that Mitchell et al. (1997) produced places potential stakeholders on three variables: Power, Legitimacy, and Urgency. Each attribute addresses concerns from various papers seeking to define "stakeholder", a task that remains notably incomplete (Key, 1999). The most explicit formulation of the questions that need to be answered in defining the term was posed early in the stakeholder discussion by Jones (1980) in a paper on Corporate Social Responsibility: "What are these groups? How many of these groups must be served? Which of their interests are most important? How can their interests be balanced? How much corporate money should be allotted to serve these interests?" Several authors have put forth their answers to these questions, as well as corollary questions. Mitchell et al. (1997) noted that, "In any case, we see those favoring a narrow definition of stakeholders as searching for a "normative core" of legitimacy so that managers can be advised to focus on the claims of a few legitimate stakeholders" (1997: 857). They show each of the various stakeholder definitions as they've evolved over time. However, they raise the point that "the broad view... is based on the empirical reality that companies can indeed be vitally affected by, or they can vitally affect, almost anyone." (1997: 867)

In addition to naming the attributes, Mitchell, et al. also break down ways of qualifying those attributes. Drawing on Etzioni's Modern Organizations (1964) and various works by Dahl (1957), Pfeffer (1981), and Weber (1947), they describe "Power" as a relationship where one party can get the other to do something it would not otherwise have done and ascribes it in three aspects: 1) Coercive, or relying on threats or violence, 2) Utilitarian, or relying on material or economic incentives, and 3) Normative, or relying on symbolic influences (1997: 869). 
Drawing on Suchman (1995), Weber (1995) and Wood (1991), Mitchell, et al. describe "legitimacy" as a generalized perception that the actions of an organization are socially desirable and state that legitimacy draws from individual, organizational, and societal perceptions. Finally, in adding "Urgency" as a model, they draw on Eyestone (1978), Wartick \& Mahon (1994), Hill \& Jones (1992), and Williamson (1985) to define urgency as the degree to which stakeholder claims call for immediate attention and ascribe it the additional aspects of time sensitivity and criticality - or the value of the relationship to the stakeholder (1997).

When Mitchell, et al. (1997) combine the variables, they arrive at a full typology in the form of a Venn diagram (Figure 1: Stakeholder Typology, Mitchell, 1997: p. 874). This topology shows three layers of stakeholders that a company could have to deal with, as well as calling someone without any of the attributes of a "nonstakeholder". Finally, to demonstrate the dynamic nature of their typology, they walk through the process as the African National Congress goes from being a "demanding" stakeholder - with no power or legitimacy (as perceived by South African companies), then becoming "dangerous" as it began to accumulate power but was still considered illegitimate by South African companies, and, finally, becoming "definitive" as it started to win national elections (1997: 879).

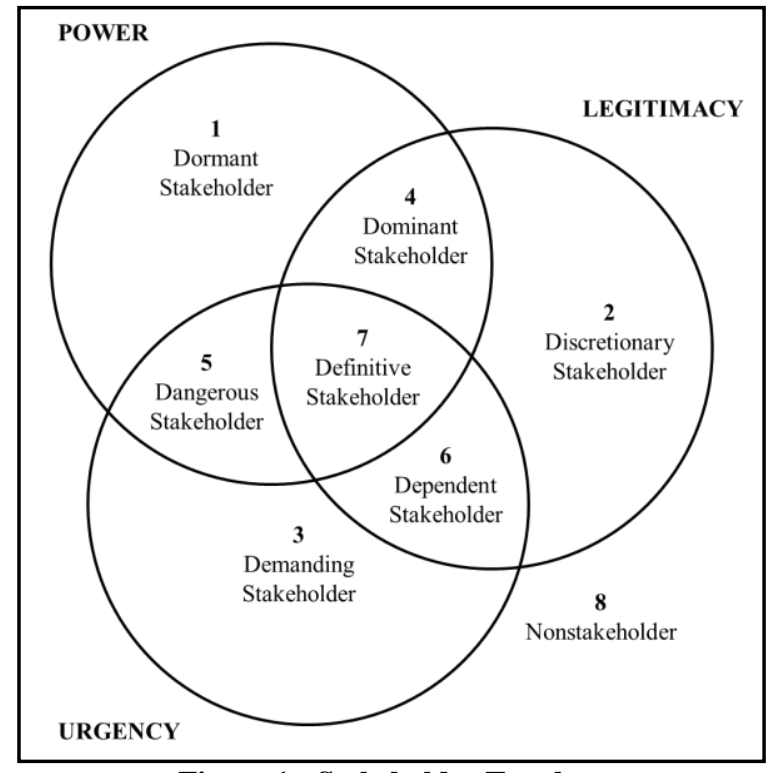

Figure 1: Stakeholder Typology

(From Mitchell, et al., 1997, with Permission)

A group of researchers, led by Mitchell, Angle, Chrisman, and Spence (2011), have published research more recently that strongly indicates that firms owned primarily by family members are more likely to view the "Power" attribute in a normative, instead of utilitarian, sense and that because family businesses reflect their family's non-economic concerns as well as their economic concerns, the sense of "Urgency" is measured differently, and "Legitimacy" often derives from heredity. Neville, Bell and Whitman's 2011 paper Stakeholder Salience Revisited: Refining, Redefining, and Refueling an Underdeveloped Conceptual Tool suggests that "Urgency", as described in Mitchell's paper, is not a key component of how management actually responds to stakeholder issues. This is a small distinction in some ways since in the Mitchell model, the urgency of the relationship is really defined by the claimant and not by the company. However, it does highlight that some companies may be failing to identify their stakeholders correctly. One paper that goes hand-in-hand with the Neville paper is a 2009 survey of managers in the US and Italy, performed by Boesso and Kumar (2009), that found that claimants with a high cumulative ranking in the "Power" and "Legitimacy" fields received the most attention from management, measured as corporate disclosures.

Another study seems to demonstrate a case for the urgency axis's inclusion - two mining accidents at a single company reviewed by Magness (2008) showed management responding strongly to the first accident while 
barely responding at all to the second one. Shareholders, however, responded strongly to the second accident and not the first, suggesting that stakeholder salience is determined through the eyes of the decision-maker and confirming the need for a dynamic model.

As stakeholder determination has been a recurring theme in the exploration of stakeholder salience, alternate methods to identify stakeholders have been proposed. In a recent paper, Sedereviciute and Valentini (2011) explored the possibility of identifying stakeholders through social media networks. This paper finds a parallel model for stakeholder identification with potential stakeholders identified as unconcerned lurkers, unconcerned influencers, concerned lurkers, and concerned influencers. These groups are then slotted into the existing groups of the Mitchell, Agle, and Wood (1997) stakeholder salience model.

\section{THE CHANGING SALIENCE OF SMOKERS AND NONSMOKERS}

Non-smokers have seen, in the general case, a transition from "non-stakeholders" of bars and restaurants in the Mitchell model to being "definitive" stakeholders. At the same time, smokers have seen their stake reduced from being "definitive" stakeholders to being "demanding" stakeholders. These two changes have occurred over the same period of time, and the improving fortunes of the one has come at the expense of the other. In Figure 2, you will see that nonsmokers prior to 1962 were effectively treated as non-stakeholders by businesses, as all businesses were expected to allow smoking, thus smokers were the definitive stakeholders. In Figure 3, you will see that nonsmoker concerns gain traction as nonsmoking and health awareness advocacies began to raise concerns about the health effects of smoking, but businesses still gave most credence to the preference of smokers who retained their definitive stakeholder status.

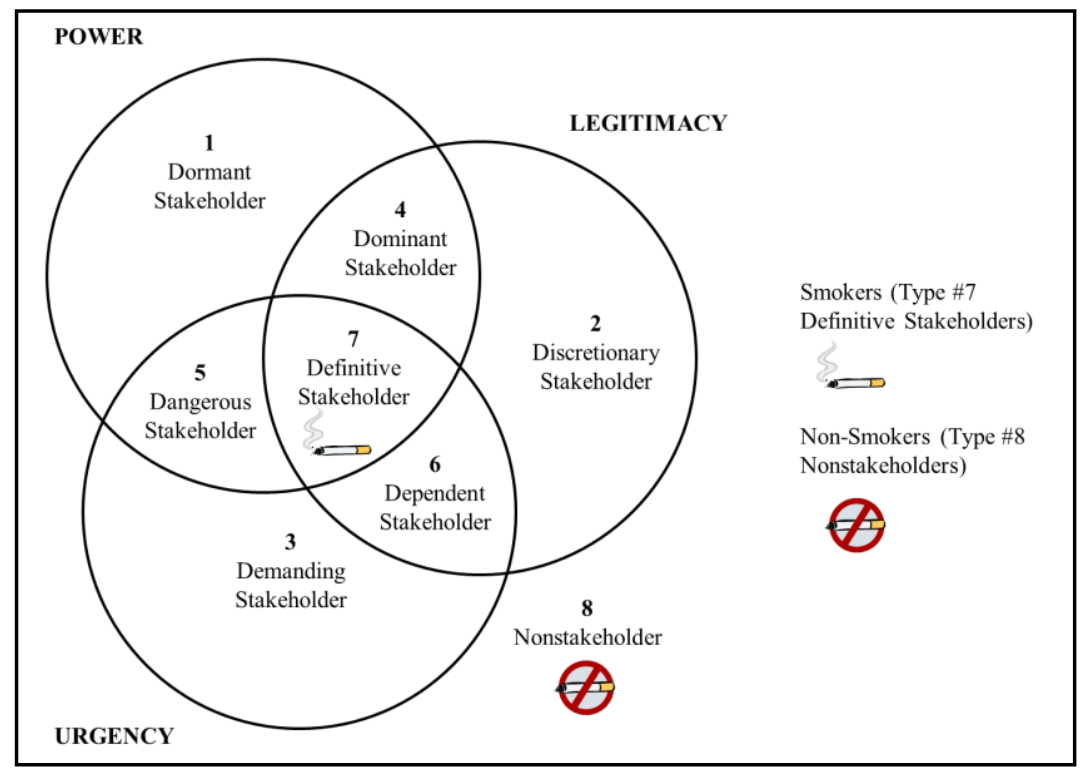

Figure 2: Smoker and Nonsmoker Stakeholder Positions Prior to 1962 (Adapted from Mitchell, et al., 1997, with Permission) 


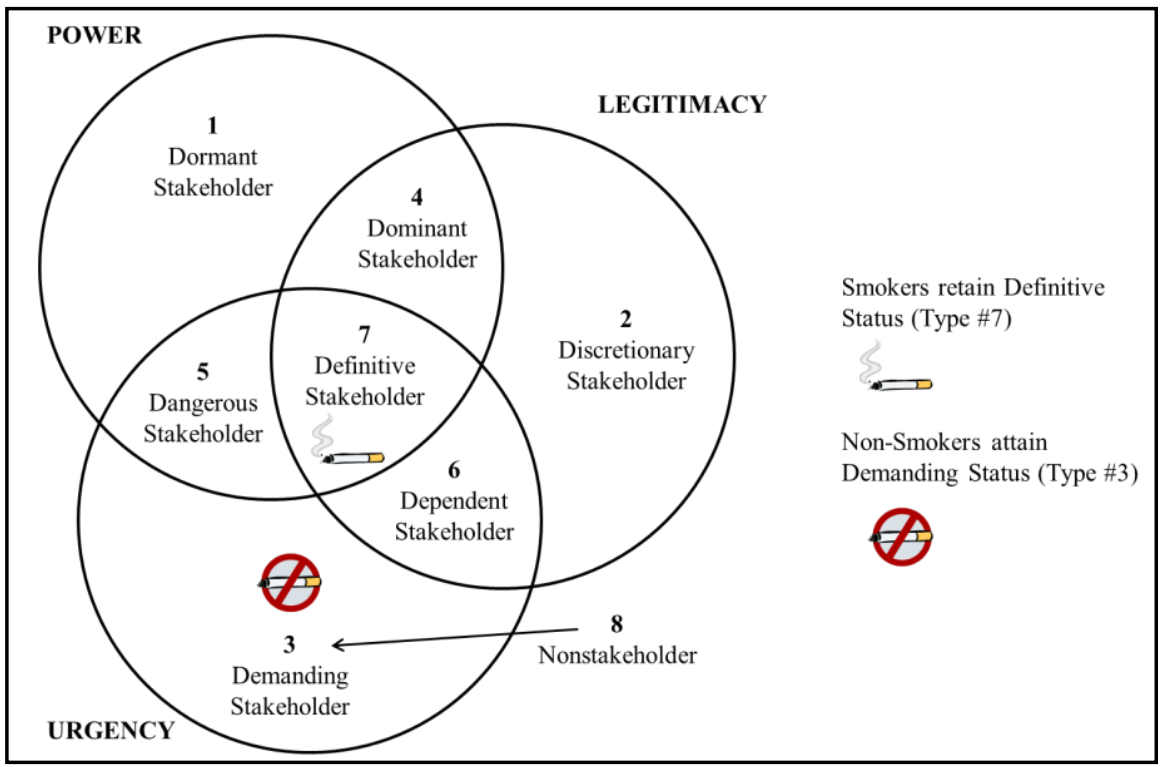

Figure 3: Nonsmokers Attain "Demanding" Stakeholder Status through Advocacy (Adapted from Mitchell, et al., 1997, with Permission)

There's not a clear tipping point where nonsmokers begin to receive societal legitimacy over smokers, but any snapshot of a moment near that midpoint would look like Figure 4. At this point in time, both smokers and nonsmokers have legitimacy; nonsmokers press their case while smokers have "power" in the form of the law (and a sense of economic might). Businesses, attempting to balance the concerns of two roughly equally salient stakeholder/customer) groups, began to place nonsmoking areas in their restaurants and smokers, for the most part, did not protest. The term "Dependent Stakeholder" that Mitchell uses to describe a stakeholder with legitimacy and urgency turns out to be very appropriate, as nonsmokers are effectively at the mercy of businesses to prohibit smoking or create nonsmoking areas. In many areas today, Figure 4 is the most representative of the current situation of the figures created. Many small municipalities and most states in the United States do not have smoking bans and restaurants in those areas are often still smoking-allowed or divided into smoking and nonsmoking.

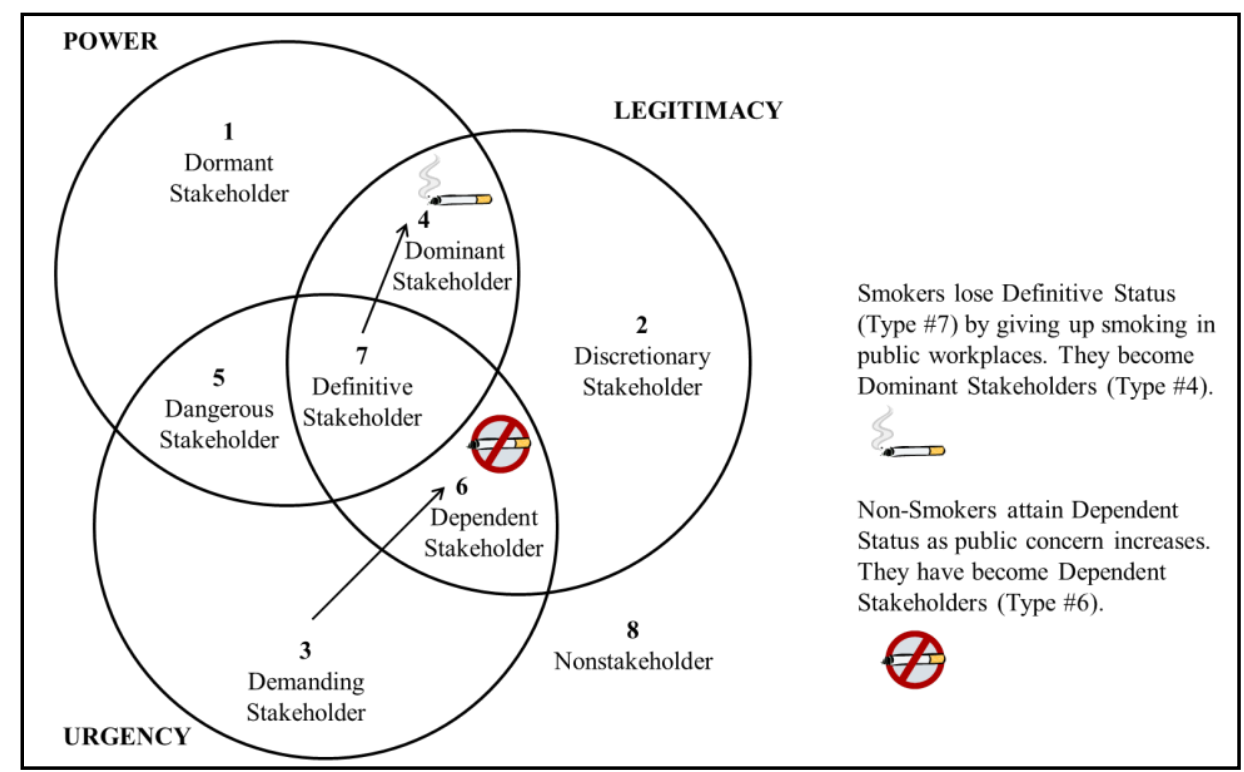

Figure 4: Nonsmokers and Smokers Compete for Legitimacy

(Adapted from Mitchell, et al., 1997, with Permission) 
In the current environment, smokers have been deprived of both their legitimacy - as smoking is considered by the public more and more to be an imposition on the health and welfare of nonsmokers - and power as the laws begin to shift to favor nonsmokers. They have, however, begun to fight against further smoking bans and incursions on their ability to smoke. In Figure 5, you will see a complete axial shift for smokers as a stakeholder group, as their appeal to businesses is now based only upon the criticality of the issue to them, and Figure 5 is intended to represent the environment in which a complete smoking ban, such as the one recently passed in our community (Birmingham, Al.), would be legislated.

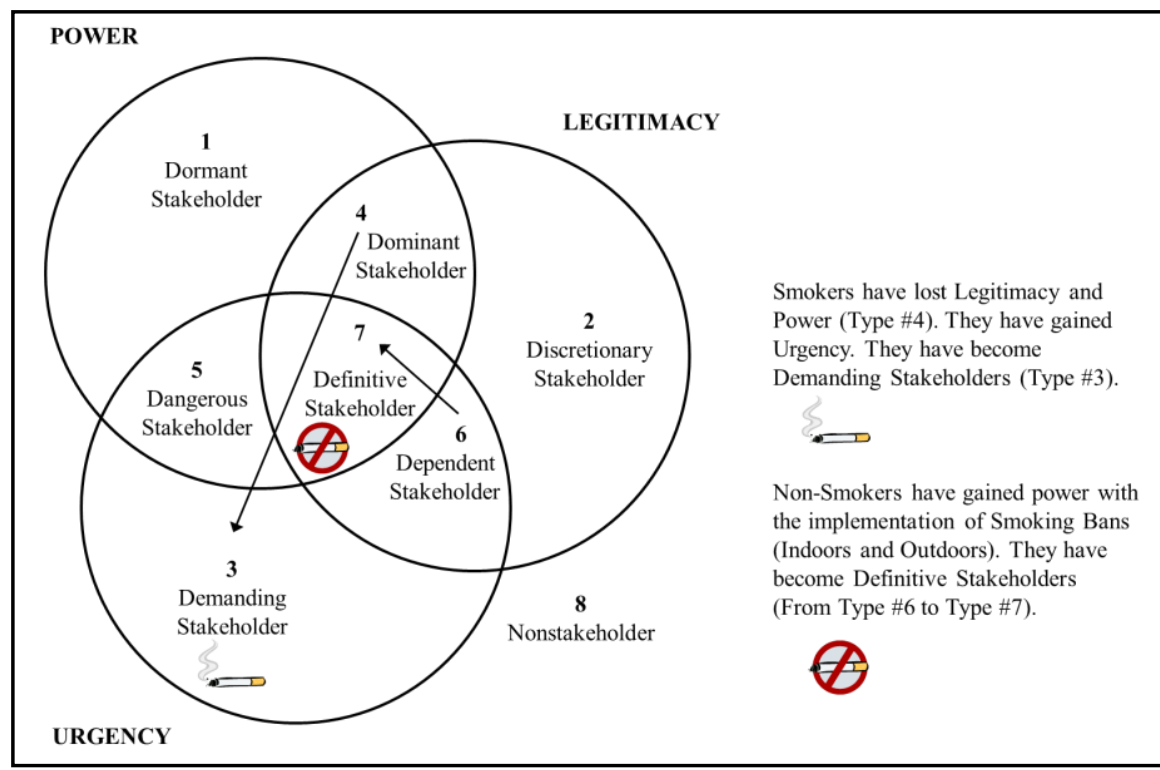

Figure 5: Smokers Swap Legitimacy and Power for Urgency, Nonsmokers Attain "Definitive" Status (Adapted from Mitchell, et al., 1997, with Permission)

\section{CONCLUSION}

The Mitchell et al. (1997) framework for determining stakeholder salience has provided an adequate framework for describing the change in smoking laws in recent years. However, this exercise only works in hindsight - a company could not use this model to predict which of the two stakeholders would end up becoming the definitive stakeholder. Externalities, such as the increasing research regarding the dangers of smoking, attempts by companies and insurers to shift health costs onto smokers, and the decreasing numbers of young smokers, are all indicators that the nonsmokers would have become the victor in this particular engagement, but the model itself provided no insight into future likelihoods. Making a subtle distinction, a case could be made that a manager might have mapped out the different possible outcomes and ranked them based on the externalities listed above and begun to shift company strategy to provide for more nonsmoking space, or to rely more heavily on nonsmokers for revenues.

The authors would like to make one final note and introduce one possibility for future research. First, they would like to point out that while research indicates that managers ignore urgent stakeholders for the sake of powerful and legitimate stakeholders, there is no research showing that this tendency is effective or valuable for the company. As a simple example, a bar that makes accommodations for nonsmokers in a smoking-allowed area will be more prepared for the eventuality of a smoking ban, which is a high likelihood in the current environment. In the future, it would be useful to track various advocacy groups as they work to transform themselves from nonstakeholders into definitive stakeholders, in the general environment, and research what attributes allow stakeholders to make that transition. For example, science has clearly demonstrated the health impacts of smoking, lending a significant weight to non-smoker efforts, while other advocacies, such as global warming activists, have failed to gain the same level of traction in the same period. Research of these transitions would help transform a descriptive model into a predictive one. 
The authors suggest that management should note the emergence of urgent stakeholders in the future, as they may gain salience in other matters that can impact company wealth. In the case of tobacco firms, they have been adversely affected by the sports and health movements, as well as medical findings on the harm caused by the use of their product. While the authors looked at research from around the world to show the economic effects of nonsmoking legislation, the application of this model currently applies to the United States and other countries who are at similar points on the timeline of nonsmoking legislation. For some firms, the use of expanded stakeholder models, such as the one used here that looks at attributes of stakeholders, can help them forecast growth as well as their legislative agenda. In this case, it would behoove firms to be open to working with groups that seek to limit the use of their product, such as nonsmokers and antismoking groups. While this may initially seem counterintuitive, it is better to control your destiny and work to craft the inevitable limitations that are going to be put on the use of cigarettes than to be left out of the legislative loop.

\section{AUTHOR INFORMATION}

Professor Susan Key holds a PhD in Business Environment and Public Policy from the University of Pittsburgh, an MBA, Juris Doctor and BA degree in English Literature and Rhetoric from the University of Illinois at UrbanaChampaign. She has been at the School of Business at the University of Alabama at Birmingham for 18 years teaching and conducting research in the fields of social issues, ethics, public policy, strategy, law and international policy. She has recently become engaged in collaborative research projects with faculty in the School of Engineering. She is the author of numerous articles and book chapters. She has also held positions in numerous nonprofit agencies, including a 3-year term as President of Pathways, a homeless women's shelter in which she oversaw the merger of two agencies. For this kind of work, Dr. Key received UAB'S Odessa Woolfolk Community Service Award in the year 2000. She was also named UAB's Outstanding Faculty Women of the Year in 2001. E-mail: susankey@uab.edu (Corresponding author)

Professor Rosalia N. Scripa holds an MS and Ph.D. in Materials Science and Engineering from the University of Florida (USA), an MS in Ceramic Engineering from the Pennsylvania State University (USA), and a BS degree in Ceramic Science from Alfred University (USA). She has been at the University of Alabama at Birmingham for 37 years teaching and conducting research in the field of ceramic and semiconductor materials. She has recently become engaged in the development of collaborative research projects with faculty in the UAB School of Business, recognizing many similar research challenges. Professor Scripa has served as a member/chair of several national level review panels for the National Science Foundation, Journal of Crystal Growth, U.S. Professor of the Year, Association of Women in Science Scholarship Program, and the NCAA Postgraduate Scholarship committee. She has been the PI/Co-Pi on over $\$ 11$ million dollars of research and equipment grants, published over 100 articles/reports and book chapters in refereed publications, and has presented the results of her research both nationally and internationally. Professor Scripa is the recipient of numerous honors and awards such as inclusion in Marquis Who's Who in American Women, Who's Who in America, and Who's Who in the World; The World Congress of Arts, Sciences and Communications Lifetime Achievement Award in recognition of a Lifetime of Contributions to Science and Education; Outstanding Woman of the $21^{\text {st }}$ Century, Distinguished Alumna Award from the University of Florida; Ellen Gregg Ingalls/UAB National Alumni Society Award for Lifetime Achievement in Teaching (Highest Teaching award at UAB); the National Research council Space Studies Board Outstanding Service Award; and inclusion in "2000 Outstanding Scientists of the $20^{\text {th }}$ Century," in honor of outstanding contributions in the field of Materials Science. E-mail: $\underline{\text { rscripa@uab.edu }}$

Mr. Robert Juneau is a graduate of the University of Alabama at Birmingham School of Business with an MBA degree. He has a special interest in social issues and ethics. He currently is a small business owner and operator.

\section{REFERENCES}

1. Adams, S., Cotti, C. and Fuhrmann, D., (2013), The short-term impact of smoke-free workplace laws on fatal heart attacks, Applied Economics, Vol. 45 No.11, pp. 1381-1390.

2. Adams, S. and Cotti, C.D. (2007), The effect of smoking bans on bars and restaurants: an analysis of changes in employment, contributions to economic analysis and policy, The B.E. Journal of Economic Analysis and Policy, Vol. 7 No. 1, pp. 13-20. 
3. Allwright, S., (2008), The impact of banning smoking in workplaces: what are the early effects?, Applied Health Economics and Health Policy, Vol. 6 No.2/3, pp. 81-92.

4. Blecher, E.H. (2006), The effects of the tobacco products control amendment ACT OF 1999 on restaurant revenues in South Africa: a panel data approach, South African Journal of Economics, Vol. 74 No. 1, pp. 123-131.

5. Boesso, G. and Kumar, K. (2009), An investigation of stakeholder prioritization and engagement: who or what really counts, Journal of Accounting \& Organizational Change, Vol. 5 No. 1, pp. 62-80.

6. Cornelsen, L. and Normand, C. (2012), Impact of the smoking ban on the volume of bar sales in Ireland evidence from time series analysis, Health Economics, Vol. 21 No. 5, pp. 551-559.

7. $\quad$ Etzioni, A. (1964), Modern Organizations, Englewood Cliffs, NJ: Prentice-Hall.

8. Jones, T. M. (1980), Corporate social responsibility revisited, redefined, California Management Review, Vol. 22 No. 3, 59-65.

9. Key, S. (1999), Toward a new theory of the firm: a critique of stakeholder theory, Management Decision. Vol. 37 No. 3/4, pp. 317-328.

10. Kvasnicka, M. and Tauchmann, H., (2012), Much ado about nothing? Smoking bans and Germany's hospitality industry, Applied Economics, Vol. 44 No. 35, pp. 453-459.

11. Magness, V., (2008), Who are the stakeholders now? An Empirical Examination of the Mitchell, Agle, and Wood Theory of Stakeholder Salience, Journal of Business Ethics, Vol. 83 No.2, pp. 177-192.

12. Mitchell, R., Agle, B., Chrisman, J. and Spence, L. (2011), Toward a theory of stakeholder salience in family firms, Business Ethics Quarterly, Vol. 21 No. 2, pp. 235-242.

13. Mitchell, R.K., Agle, B.R. and \& Wood, D.J. (1997), Toward a theory of stakeholder identification and salience: defining the principle of who and what really counts, Academy of Management Review, Vol. 22 No.4, pp. 853-886.

14. Neville, B., Bell, S. and Whitwell, G. (2011), Stakeholder salience revisited: refining, redefining, and refueling an underdeveloped conceptual tool, Journal of Business Ethics, Vol. 102 No. 3, pp. 357-378.

15. Royal College of Physicians of London. (1962), Smoking and Health: Summary Report, On Smoking in Relation to Cancer of the Lung and Other Diseases, Pitman Pub. Corp., New York.

16. Sedereviciute, K. and Valentini, C. (2011), Towards a more holistic stakeholder analysis approach: mapping known and undiscovered stakeholders from social media, International Journal of Strategic Communication, Vol. 5 No. 4, pp. 221-239.

17. Taylor, T., Cooper, T., Hernandez, N., Kelly, M., Law, J. and Colwell, B. (2012), A smoke-free Paso del Norte: impact over 10 years on smoking prevalence using the behavioral risk factor surveillance system, American Journal of Public Health, Vol.102 No. 5, pp. 899-908.

18. U.S. Public Health Service. (1964), Smoking and Health: Report of the Advisory Committee to the Surgeon General Public Health Service, U.S. Government Printing Office, Washington, DC. 